\title{
The diverging patterns of life satisfaction between families: A latent profile analysis in dual-earner parents with adolescents
}

\author{
Berta Schnettler ${ }^{1,2,3,4}$ (D) Klaus G. Grunert ${ }^{5,6} \cdot$ Ligia Orellana $^{2,4} \cdot$ Horacio Miranda ${ }^{1} \cdot$ Germán Lobos $^{3,7}$ • \\ Edgardo Miranda-Zapata ${ }^{4,8} \cdot$ María Lapo $^{3} \cdot$ Clementina Hueche $^{4}$
}

Accepted: 22 December 2020 / Published online: 2 January 2021

(C) The Author(s) 2021

\begin{abstract}
This study identifies family profiles based on the level of life satisfaction (LS) in mothers, fathers and adolescents, and variables related to their family, food, and work life. The sample was composed of 303 families of dual-earner parents (mothers' mean age $=40.9$ years, $\mathrm{SD}=7.4$, fathers' mean age $=43.2$ years, $\mathrm{SD}=7.2$ ) and one of their children aged between 10 and 17 years (mean age $13.3, \mathrm{SD}=2.4,51.5 \%$ female). A Latent Profile Analysis (LPA) was used to identify five family profiles. Profiles differed in LS, satisfaction with family life (SWFaL), satisfaction with food-related life (SWFoL), family functioning, both parents' worklife balance and their perception of the financial situation of the household. Balanced and imbalanced families in terms of LS differed in the three family members' LS and SWFaL, mothers' and children' SWFoL and family functioning, and both parents' perception of financial situation. These results contribute to understanding the heterogeneity of life satisfaction dynamics between and within dual-earner families.
\end{abstract}

Keywords Life satisfaction $\cdot$ Family $\cdot$ Food $\cdot$ Work-life balance $\cdot$ Profiles

Family relationships are strongly associated with the individuals' well-being (Thomas, Liu, \& Umberson, 2017). Subjective well-being (SWB, Diener \& Biswas-Diener, 2000 ) is the person's assessment of their own life, which involves an emotional component, encompassed by the

Berta Schnettler

berta.schnettler@ufrontera.cl

1 Facultad de Ciencias Agropecuarias y Forestales, Universidad de La Frontera, Temuco, Chile

2 Scientific and Technological Bioresource Nucleus (BIOREN-UFRO), Universidad de La Frontera, Temuco, Chile

3 Universidad Católica de Santiago de Guayaquil, Guayaquil, Ecuador

4 Centro de Excelencia en Psicología Economía y del Consumo, Núcleo Científico Tecnológico en Ciencias Sociales, Universidad de La Frontera, Temuco, Chile

5 MAPP Centre, Aarhus University, Aarhus, Denmark

6 University of Vaasa, Vaasa, Finland

7 Facultad de Economía y Negocios, Universidad de Talca, Talca, Chile

8 Núcleo Científico Tecnológico en Ciencias Sociales, Laboratorio de Investigación en Ciencias Sociales Aplicadas (LICSA), Universidad de La Frontera, Temuco, Chile construct of happiness (Arita, 2005), and a cognitive component, satisfaction with life. Family relationships contribute to SWB not only because they are included in the individual's overall assessment of their life, but because family members share characteristics and conditions that can account for similar assessments. In the case of life satisfaction, there is evidence indicating that life satisfaction levels are correlated between members of the same family (Carlsson, Lampi, Li, \& Martinsson, 2014; Dobewall et al., 2019; Headey, Muffels, \& Wagner, 2014; Ma, 2016; Maftei, Holman, \& Cârlig, 2020; Mauno, Hirvonen, \& Kiuru, 2018; Thege, Littvay, Tarnoki, \& Tarnoki, 2017).

Previous studies that have focused on life satisfaction in family members have been mostly conducted in North America, Europe, and Asia (Headey et al., 2014; Liu \& Cheung, 2015; Pollmann-Schult, 2014; Terrazas-Carrillo, McWhirter, \& Muetzelfeld, 2016). This overrepresentation of developed countries in the literature (see $\mathrm{Rad}$, Martingano, \& Ginges, 2018) poses the question about the generalizability of life satisfaction dynamics in families from developing countries. For instance, Terrazas-Carrillo et al. (2016) have reported that having children has been associated with lower levels of life satisfaction in working parents from developed countries, and with higher levels in working parents from Latin American countries. These authors have 
explained that this difference relates to cultural values, as Latin American parents place higher importance on having children over work and economic success, whereas these factors are not considered mutually exclusive in developed countries.

Moreover, traditional gender roles are changing in Latin America as more women enter the workforce, which entails changes in men's and women's living arrangements and subsequent satisfaction in their work, family, and other life domains (Terrazas-Carrillo et al., 2016). Nevertheless, development towards gender equality does not manifest with the same strength in Latin American as in more developed regions. Latin American dual-earner parents still uphold traditional roles in the home (Schnettler et al., 2019). Women face high pressure to prioritize a domestic role as they balance a work role (Terrazas-Carrillo et al., 2016), and are still the main person responsible for the food-related tasks and family meals, even if they have paid employment (Schnettler et al., 2020); in contrast, men's work role is considered a contribution to the family (Bartley, Blanton, \& Gilliard, 2005). Taken together, findings have shown that variables which influence SWB can vary between countries and cultures in how they manifest (e.g. Davis, Rudy, Su-Russell, \& Zhang, 2018; Telef \& Furlong, 2017). Thus, research is needed to better understand the specific conditions of life satisfaction patterns among family members in the Latin American context.

These conditions for working parents, and their associated satisfaction levels, can be expected to be linked to their children's well-being. However, little is known about the extent to which children of dual-earner parents in Latin America fare in terms of satisfaction levels compared to their parents. This gap in knowledge is particularly pressing for the stage of adolescence, in which children become independent from their parents, finding other sources of support (Tisdale \& PittCatshupes, 2012), and making decisions of their own (e.g. regarding what to eat, Schnettler et al., 2019). At the same time, adolescents continue to rely on their parents and, in turn, can provide them with emotional and instrumental support (Tisdale \& Pitt-Catshupes 2012). For parents, their children's adolescence can be challenging for their well-being (Meier, Musick, Fischer, \& Flood, 2018), as parents must fulfill demands to promote their child's healthy development (Davis et al., 2015).

While there is evidence of correlation between life satisfaction levels among family members, other studies have explored the nuances of these relations. Research shows that parents' own well-being is only weakly related to their children's (Augustijn, 2020; Bedin \& Sarriera, 2014; Casas et al., 2012), and that mothers' life satisfaction has greater influence than fathers' on their children's life satisfaction (Chi et al., 2019; Dobewall et al., 2019; Headey et al., 2014; Richter, Bondü, Spiess, Wagner, \& Trommsdorff, 2018; Schnitzlein \& Wunder, 2016). In other words, while some families show similar patterns of life satisfaction (i.e. homogeneity), other families show diverging patterns of life satisfaction between family members (i.e. heterogeneity).

The findings above suggest that divergent life satisfaction levels may be found between families, and between members of a single family. Similar patterns of life satisfaction between family members have been explained by genetic personality traits (Carlsson et al., 2014; Dobewall et al., 2019; Headey et al., 2014; Thege et al., 2017), but also by family-related environmental aspects, such as parental influences, life events and shared experiences (Headey et al., 2014; Ma, 2016; Mauno et al., 2018; Thege et al., 2017). However, familyrelated environmental aspects may differ between families as well as affect in different ways the members of the same family. In this case, it might occur that, in some families, parents can have higher levels of life satisfaction than their children or vice versa; or one parent may have different levels of life satisfaction than the other parent and children. Explanations for these diverging patterns of life satisfaction have received scarce attention in the literature, in particular in different-sex dual-earner couples, who need to fulfil multiple demands from the home and work domains (Matias et al., 2017a, b).

To reconcile the diverging findings on life satisfaction levels among family members, it is useful to examine family units and variables associated with their members' life satisfaction. Most studies have used a variable-centered approach to examine relationships between life satisfaction and related variables. In contrast, a person-centered approach identifies differences among people, categorizing them as distinct groups that are internally homogeneous (Bourdier et al., 2018; Vieira, Matias, Lopez, \& Matos, 2018). Furthermore, life satisfaction studies have been conducted using individuallevel analyses; although this has proven a useful approach, it is limited in providing information about the context in which these variables are related for one individual.

Examining the levels of life satisfaction of different family members at the same time can help expand the scope to understand the diverse influences between and within families. Therefore, this study adopts a triadic focus, centering on mother, father, and adolescent. This triadic approach is supported by the Family Systems Theory (Kerr \& Bowen, 1988), which posits that individuals in a family are interdependent on one another (Vieira et al., 2018). Moreover, the approach of this study also relies on crossover processes, that is, the transmission of experiences and related emotions between individuals who living in the same environment (Bakker \& Demerouti, 2013).

A starting point to understand the heterogeneity of life satisfaction between families is the Bottom-Up theoretical approach to life satisfaction. According to this approach, life satisfaction depends on the person's assessment of their different life domains (Pavot \& Diener, 2008). Evidence shows that parents' satisfaction in domains such as work (Dobewall 
et al., 2019; Mauno et al., 2018), family, and even food (Schnettler et al., 2017a, b) are associated with their own life satisfaction. These studies also report that parents' satisfaction in different domains is also associated with their children's life satisfaction. This finding suggests a crossover effect in families, that is, a transmission of experiences from one domain to another between close persons sharing the same environment (Bakker \& Demerouti, 2013).

This crossover effect, along Family Systems Theory (Kerr $\&$ Bowen, 1988), support the expectation of a balanced family, that is, one whose members share similar levels of life satisfaction. On the other hand, there is literature showing no crossover effects from parents to children (Luebbe, Fussner, Kiel, Early, \& Bell, 2013) and suggesting that life satisfaction levels can differ among family members (Bedin \& Sarriera, 2014; Casas et al., 2012; Chi et al., 2019; Dobewall et al., 2019; Headey et al., 2014; Richter et al., 2018; Schnitzlein $\&$ Wunder, 2016). In addition, research shows that satisfaction in specific domains is not homogenous between families (Schnettler et al., 2017a, b; Schnettler et al., 2018a, b; Vieira et al., 2018). This evidence points to diverging life satisfaction levels among family members, but fewer published studies address these imbalanced families.

One relevant domain to understand life satisfaction in families is, precisely, the family domain. The literature suggests two specific aspects to account for in this regard: Family functioning and satisfaction with family life (SWFaL). The construct of family functioning (Botha, Booysen, \& Wouters, 2018) comprises family interactions and relationships based on conflict, cohesion, adaptability, organization, and communication (Alderfer et al., 2007). It has been reported that positive family functioning results in higher life satisfaction in adults and adolescents (Jia et al., 2018). The second construct, SWFaL, is the person's conscious cognitive judgment of their family life based on their own subjective criteria (Zabriskie \& McCormick, 2003) and it has also been positively associated with life satisfaction in adolescents and adults (Schnettler, Lobos, et al., 2017a; Schnettler, Miranda-Zapata, et al., 2017b; Schnettler et al., 2018; TerrazasCarrillo et al., 2016). SWFaL has been also related to satisfaction in other domains such as work and finances (Botha et al., 2018; Tammelin, Malinen, Rönkä, \& Verhoef, 2017), and, less intuitively, food (Schnettler, Lobos, et al., 2017a; Schnettler, Miranda-Zapata, et al., 2017b).

Satisfaction with life and family life in working parents have been associated with their work-life balance (WLB, Headey et al., 2014). WLB is defined as the person's perception of how well their work and other life roles are balanced (Haar, Russo, Suñe, \& Ollier-Malaterre, 2014). Research shows that employees who perceive good balance between their work and life roles tend to experience higher levels of life satisfaction (Greenhaus \& Powell, 2006; Haar, 2013; Haar et al., 2014; Schnettler et al., 2020). In dual-earner households, studies show that parents' WLB affects not only their own well-being, but also the well-being of their partner (Bakker \& Demerouti, 2013; Schnettler et al., 2020) and children (Mauno et al., 2018; Schnettler, Miranda-Zapata, et al., 2018). It has also been reported that poor WLB in parents affects their parenting attitudes (Vieira, Matias, Lopez, \& Matos, 2016), which negatively influence the parent-child interaction (Tammelin et al., 2017).

Another family-related aspect associated with life satisfaction is the family socioeconomic status (SES) and its financial situation (Conger \& Conger, 2008; Ma, 2016). Studies show that these two variables have a large influence on parents' life satisfaction and their adolescent children's well-being (Dobewall et al., 2019; Ma, 2016; Pollmann-Schult, 2014; Rajani, Skianis, \& Filippidis, 2019). There is also evidence of negative relationships between these two variables and satisfaction in the food (Schnettler, Grunert, et al., 2018a, b) and family (Botha et al., 2018) domains. Other research has associated a poor family economic situation with higher levels of work-family conflict (Tammelin et al., 2017). In general terms, Thomas et al. (2017) report that a lower SES can produce and exacerbate family distress, while families from higher SES can provide more financial and emotional support to its members.

One last domain that can be linked to life satisfaction among family members is satisfaction with food-related life (SWFoL). SWFoL is defined as the person's overall assessment of their food habits (Grunert, Dean, Raats, Nielsen, \& Lumbers, 2007). Beyond nutritional aspects, SWFoL expands on the social aspects of food preparation and consumption, including when, how and with whom food and meals are shared. Higher SWFoL has been positively associated with higher life satisfaction in adolescents and adults (Grunert et al., 2007; Schnettler et al., 2017a, b; Schnettler, Miranda-Zapata, et al., 2017b; Schnettler, Miranda-Zapata, et al., 2018; Vaqué-Crusellas, González, \& Casas, 2015). Research in family settings also has shown that higher levels of SWFoL are associated with more frequent family meals and higher family cohesion in adolescents and adults (Schnettler, Grunert, et al., 2018a, b; Schnettler, Lobos, et al., 2017a). However, not all families have the chance to share family meals (Nepper \& Chai, 2016), or these meals become difficult as they are carried out in contexts of poor family functioning (Utter et al., 2018), family financial constraints (Rasmussen, Pedersen, Johnsen, Krølner, \& Holstein, 2018) and the parents' low balance between work and family life (Sharif, Alcalá, Albert, \& Fischer, 2017). It can be expected then that a supportive family environment (i.e. satisfactory and wellfunctioning, as well as less financially constrained) can be linked to a higher SWFoL.

Taken together, the aforementioned studies have established that life satisfaction is associated with the family and work domains, and even the food domain, but these relationships have been mostly examined at the individual level. This study adopts a triadic focus to explore the heterogeneity of life satisfaction between families (Schnettler, Grunert, et al., 
2018a, b; Schnettler, Lobos, et al., 2017a; Vieira et al., 2018), and how distinct experiences of family members in diverse life domains contribute to this heterogeneity. Dual-earner families were chosen for this study, within a Latin American context which may influence the experiences in work, family and food domains distinctly for mothers and fathers. Furthermore, families with adolescents were chosen because in this life stage, children remain connected to their parents (Thomas et al., 2017) but conflicts between them arise, partly due to the changes inherent to the adolescent individual and to parenting practices (Pérez-Fuentes et al., 2019). Efforts to face and resolve these conflicts, in turn, can put a toll on parents' life satisfaction (Pollmann-Schult, 2014).

Using family profiles, different levels of life satisfaction can be characterized while accounting for associated conditions in the family, food, and work domains. For this study, the family domain comprises family functioning, SWFaL, and SES and perceived financial situation of the household; the food domain includes SWFoL; and the work domain, parents' WLB. Family profiles were built in terms of three family members' assessment of life satisfaction (i.e. life satisfaction scores), classifying mother, father, and one adolescent child as families based on their levels of life satisfaction. Subsequently, related variables to the family, work, and food domains were explored for each profile. Lastly, a third distinction was made by comparing those families whose members have similar or differing levels of life satisfaction (i.e. balanced and imbalanced families, respectively).

The objectives of this study were: 1) To identify family profiles based on the level of life satisfaction of working mothers and fathers and their adolescent children; 2) To determine whether profiles differ in terms of the three family members' satisfaction with family and food-related life, family functioning, and both parents' work-life balance and their perception of their SES and household financial situation; 3) To examine whether family members within each profile differ in levels of the variables above; and 4) To compare families that are balanced in terms of their satisfaction with life with those that are imbalanced.

\section{Method}

\section{Sample and Procedure}

A sample of 303 families was recruited using non-probabilistic sampling. These families were composed of dual-earner couples, married or cohabiting, with at least one child between 10 and 17 years old, in Temuco, Chile (Table 1). Families were contacted through seven schools that serve socioeconomically diverse populations. Five-hundred forty-nine families were contacted by trained interviewers, who explained the study objectives and the strict confidential treatment of the obtained information. Then, the interviewers provided detailed information about the questionnaires and asked if both parents and one of their children between 10 and 17 years of age wanted to participate in the study. A total of 303 parents agreed to participate in the study, resulting in a response rate of $55.2 \%$.

Families that agreed to participate in this study were visited in their homes by trained interviewers between May and August 2017. After parents signed informed consent and adolescents signed assent forms, the questionnaires were personally administered separately to each family member. This study is part of a larger research on eating habits and subjective well-being in Chilean families, and it was approved by the Ethics Committee of [information has been removed for blind review]. A pilot test was conducted with 20 father-motheradolescent triads following the same recruitment and questionnaire application methods. This procedure was deemed effective and no changes were made in the recruitment nor the data collection process.

There was no missing data, as the questionnaires were administered by trained interviewers to ensure that all questions were responded. No family nor individual participants withdrew from the study. Hence, the analysis conducted included all responses of the 303 mothers, fathers, and adolescents.

\section{Measures}

The following instruments were answered by the mothers, fathers, and adolescents:

Satisfaction with Life Scale (SWLS, Diener, Emmons, Larsen, \& Griffin, 1985) The SWLS is composed of five items grouped into a single dimension to evaluate individuals' overall assessment of their own life (e.g. "In most ways my life is close to my ideal"). The Spanish version of the SWLS was used (Schnettler, Miranda, Sepúlveda, \& Denegri, 2011), which has shown good internal consistency in previous studies with adolescents (Cronbach's $\alpha=.90-.91$ ) and adults (Cronbach's $\alpha=.89-.90$ ) in Chile (Schnettler, Grunert, et al., 2018a, 2018b; Schnettler, Lobos, et al., 2017a). Respondents were asked to indicate their degree of agreement with each statement using a 6-point Likert scale (1: completely disagree; 6: completely agree). In this study, the SWLS showed good internal reliability (Ordinal alpha mothers $=.91$, fathers $=.92$, adolescents $=.90$ ). SWLS scores were obtained by summing up the scores from the five items.

Satisfaction with Food-related Life (SWFoL, Grunert et al., 2007) The SWFoL consists of five items grouped into a single dimension that evaluates individuals' overall assessment of their food and eating habits (e.g. "Food and meals are positive elements"). The Spanish version of the SWFoL was used (Schnettler et al., 2011), which has shown good internal consistency in studies with adolescents (Cronbach's $\alpha=.89-.91$ ) 
and adults (Cronbach's $\alpha=.76-.86$ ) in Chile (Schnettler, Grunert, et al., 2018a, b; Schnettler, Lobos, et al., 2017a). Respondents were asked to indicate their degree of agreement with each statement using a 6-point Likert scale (1: completely disagree; 6: completely agree). In this study, the SWFoL showed good internal reliability (Ordinal alpha mothers = .90 , fathers $=.90$, adolescents $=.90)$. SWFoL scores were obtained by summing up the scores from the five items.

Satisfaction with Family Life (SWFaL, Zabriskie \& McCormick, 2003) The SWFaL is an adaptation of the SWLS (Diener et al., 1985 ) in which the words "family life" replace the word "life" in each of the five original SWLS items. The Spanish version of the SWFaL was used (Schnettler, Miranda-Zapata, et al., 2017b), which has shown good internal consistency in studies with adolescents (Cronbach's $\alpha=.90-.92)$ and adults (Cronbach's $\alpha=$ .91-.92) in Chile (Schnettler, Grunert, et al., 2018a, b; Schnettler, Lobos, et al., 2017a). Respondents were asked to indicate their degree of agreement with each of the statements using a 6-point Likert scale (1: completely disagree; 6 : completely agree). In this study, the SWFaL showed good internal reliability (Ordinal alpha mothers $=.91$, fathers $=.94$, adolescents $=.90)$. SWFaL scores were obtained by summing up the scores from the five items.

The discriminant validity of the SWLS, SWFoL and SWFaL has been previously supported in samples of adolescents and adults in Chile (Schnettler, Grunert, et al., 2018a, b; Schnettler, Lobos, et al., 2017a).

\section{The Family Adaptation, Partnership, Growth, Affection, and Resolve scale (Family APGAR, Smilkstein, 1978) The Family} APGAR is a five-item measure designed to assess family function in diverse contexts (Benítez, Pino, Padilla, \& Cuevas-Parra, 2016). The scale has five components of family support: Adaptability, Partnership, Growth, Affection and Resolve. The Spanish version of the Family APGAR scale was used (Bellón, Delgado, Luna, \& Lardelli, 1996), which has shown good or adequate levels of internal consistency in adolescents (Cronbach's $\alpha=.80$, Moreno \& Londoño-Pérez, 2017) and adults (Cronbach's $\alpha=.77$, Gómez \& Ponce, 2010) in South American countries. Each item is rated on a threepoint Likert scale, ranging from 0 : hardly ever to 2 : almost always. In this study, the family APGAR showed at least acceptable internal reliability (Ordinal alpha mothers $=.88$, fathers $=.92$, adolescents $=.77$ ). The Family APGAR scores were obtained by summing up the scores from the five items.

The following scale was answered only by the mothers and fathers:

Work-life Balance (WLB, Haar, 2013) The WLB is a scale composed of three items grouped into a single dimension (e.g. "I manage to balance the demands of my work and personal/family life well") to assess an individual's perception of how well their work and other life roles are balanced. The
Spanish version of the WLB was used (Schnettler, Grunert, et al., 2018a, b), which showed good levels of internal consistency in adult samples (Cronbach's $\alpha=.82-.87$ ). Respondents were asked to indicate their degree of agreement with the three statements using a 5-point Likert scale (1: completely disagree to 5 : completely agree). In this study the WLB scale showed good internal reliability (Ordinal alpha mothers $=.87$, fathers $=.91$ ). The WLB scores were obtained by summing up the scores from the three items.

The three family members were asked about their age. Mothers were asked about the number of family members and the number of children. Mothers and fathers were asked about their perception of their current household financial situation. Education level and occupation of the head of household were used to determine socioeconomic status (SES) (Adimark, 2004).

\section{Data Analysis}

The current study used a two-step process to identify family profiles based on the level of life satisfaction of working mothers and fathers and their adolescent children. The first step was to group families based on mother's, father's, and adolescent's SWLS scores. A Latent Profile Analysis (LPA) for continuous variables was used to estimate the number of profiles associated with Life Satisfaction scores of motherfather-adolescent triads (Vermunt \& Magidson, 2002). Given the exploratory nature of the current study, the LPA models were tested iteratively, i.e., multiple latent profile models (1-7 groups) were estimated and examined to find the best-fitting model, using the SWLS scores for mothers, fathers and adolescents. The best-fitting model (i.e., the optimal number of profiles) was selected based on the Bayesian information criterion (BIC), the consistent Akaike's information criterion (CAIC) and the entropy test. Lower BIC and AIC scores indicate better fit. Entropy refers to the degree of certainty regarding the inclusion of participants in one profile; entropy values above 0.80 are considered acceptable, as values near 1 mean a higher degree of certainty (Muthén \& Muthén, 2000; Vermunt \& Magidson, 2002). The LPA was conducted using the Latent Gold 5.1 statistics software (Statistical Innovations Inc.).

After the three family members were grouped into the five profiles based on their SWLS scores, the second step of the analysis involved characterizing these profiles based on statistical differences found in the variables concurrent with these scores. Pearson's $\mathrm{Chi}^{2}$ test and a one-factor analysis of variance were used to examine whether profiles differed in terms of the three family members' satisfaction with family and food-related life, family functioning, and both parents' work-life balance and their perception of their SES and household financial situation. Pearson's $\mathrm{Chi}^{2}$ test was applied to the discrete variables and a one-factor analysis of variance for the continuous variables. 
Continuous variables for which Levene's statistic indicated homogeneous variances $(p \leq .001)$ were subjected to Tukey Multiple Comparisons test, while those with non-homogeneous variances $(p \leq .05$ or $p \leq .001)$ were subjected to Dunnett's T3 multiple comparisons test.

The analysis of within-family differences was used to observe the extremes of heterogenous and non-heterogenous families in terms of their life satisfaction. To compare profiles in which life satisfaction was similar among family members with those in which life satisfaction differed among family members, an index of life satisfaction balance was calculated. This index was obtained by summing the absolute value of all three dyadic differences in the life satisfaction score between family members (father/mother, father/adolescent, mother/adolescent). Families were subsequently grouped according to quartiles in the resultant score.

According to the Circumplex Model of Marital and Family Systems (Olson, 2000; Olson, Waldvogel, \& Schlieff, 2019), balanced couples and families tend to be more functional (happy and successful), cohesive and communicative than imbalanced systems. The evidence shows that balanced families have greater levels of life satisfaction than imbalanced families (Szcześniak \& Tułecka, 2020; Turkdogan, Duru, \& Balkis, 2019). Therefore, only the first and fourth quartiles were used in this analysis as we were interested in differences between families with homogenous life satisfaction levels (balanced family) compared to families with heterogeneous life satisfaction levels (imbalanced families). To evaluate differences between balanced and imbalanced families, Student's t test for independent samples was conducted for continuous variables, and a Chi-squared test for discrete variables. Except for the LPA analysis, analyses were conducted using the Statistical Package for Social Sciences (IBM SPSS) v. 23.

\section{Results}

\section{Sample Description}

Table 1 shows the sociodemographic characteristics of the sample, and the mothers' and fathers' perceptions of their household's current financial situation. Table 1 also includes
Table 1 Sample characteristics ( $n$ $=303$ )

\begin{tabular}{|c|c|c|}
\hline \multicolumn{2}{|l|}{ Characteristic } & \multirow{2}{*}{$\begin{array}{l}\text { Total sample } \\
40.9(7.4)\end{array}$} \\
\hline Mother's age [Mean $(S D)]$ & & \\
\hline Father's age [Mean $(S D)]$ & & $43.2(7.2)$ \\
\hline Number of family members [Mean $(S D)]$ & & $4.3(1.1)$ \\
\hline Number of children $[$ Mean $(S D)]$ & & $2.4(1.0)$ \\
\hline Interviewed children age [Mean $(S D)]$ & & $13.3(2.4)$ \\
\hline \multirow[t]{2}{*}{ Interviewed children gender $(\%)$} & Female & 51.5 \\
\hline & Male & 48.5 \\
\hline \multirow[t]{5}{*}{ Socioeconomic status (\%) } & High and upper-middle & 11.2 \\
\hline & Middle-Middle & 20.8 \\
\hline & Lower-Middle & 37.0 \\
\hline & Low & 21.5 \\
\hline & Very low & 9.6 \\
\hline \multirow[t]{5}{*}{ Mother current financial situation (\%) } & Very difficult & 7.3 \\
\hline & Difficult & 23.4 \\
\hline & Regular & 45.9 \\
\hline & Good & 20.8 \\
\hline & Very Good & 2.6 \\
\hline \multirow[t]{5}{*}{ Father current financial situation (\%) } & Very difficult & 6.6 \\
\hline & Difficult & 25.1 \\
\hline & Regular & 43.9 \\
\hline & Good & 21.8 \\
\hline & Very Good & 2.6 \\
\hline \multirow{3}{*}{ Satisfaction with life [Mean $(S D)]$} & Mother & $24.9(4.2)$ \\
\hline & Father & $25.2(4.0)$ \\
\hline & Adolescent & $25.5(4.1)$ \\
\hline \multirow[t]{3}{*}{ Satisfaction with food-related life [Mean $(S D)]$} & Mother & $23.5(4.6)$ \\
\hline & Father & $24.2(4.1)$ \\
\hline & Adolescent & $24.4(4.7)$ \\
\hline \multirow[t]{3}{*}{ Satisfaction with family life [Mean (SD)] } & Mother & $25.0(4.6)$ \\
\hline & Father & $25.4(4.3)$ \\
\hline & Adolescent & $25.7(4.5)$ \\
\hline \multirow[t]{3}{*}{ Family APGAR [Mean (SD)] } & Mother & $8.5(1.6)$ \\
\hline & Father & $6.9(1.6)$ \\
\hline & Adolescent & $6.6(1.5)$ \\
\hline \multirow[t]{2}{*}{ Work-life balance [Mean (SD)] } & Mother & $12.5(2.2)$ \\
\hline & Father & $12.1(2.3)$ \\
\hline
\end{tabular}


each family member's average SWLS, SWFoL and SWFL scores, which indicated that the three family members are satisfied with their food-related life, family life and with their overall life. The three family members' family APGAR scores and the mothers' and fathers' WLB average scores are also shown. Mothers had significantly lower average scores on the SWFoL than fathers and children $(p=.043)$. Mothers had significantly higher average scores in the family APGAR scale than fathers and adolescents $(p \leq .001)$. No significant differences between the family members were found in the rest of the variables included in this study $(p>.100)$.

\section{Latent Profile Analysis of Families}

An initial run of 1-7 clusters was analyzed with the SWLS scores of the three family members. The five-cluster model (Table 2) had the best fit because it had the lowest BIC and CAIC values as well as a value in the entropy test above 0.80 (Muthén \& Muthén, 2000; Vermunt \& Magidson, 2002). The Wald statistics associated significance levels were below .001, which is evidence that the SWLS score for the three family members were useful for segmenting: Mother's SWLS (robust Wald statistic $=251.82, p<.001$ ), father's SWLS (robust Wald statistic $=45.21, p<.001)$ and adolescent's SWLS (robust Wald statistic $=315.45, p<.001$ ). The percentage of variance explained was $61.30 \%$ for mother's SWLS, $27.39 \%$ for father's SWLS and $32.46 \%$ for adolescent's SWLS. Since there are no previous studies in Chile that assign the parameters of a LPA statistical power analysis from a reference population, tables were reviewed to assess an index based on the number of classes in the latent profile analysis. This procedure was proposed by Tein, Coxe, and Cham (2013), who worked with sample sizes similar to those used in this study with medium-high effect sizes.

The resulting profiles are described below, labelled based on their average SWLS scores (Fig. 1). Table 3 shows the scores of the continues variables with statistical differences used to describe the family profiles, while Table 4 shows differences between profiles according to the discrete variables.

Latent Profile 1: Families with medium life satisfaction (31.22\% of the Sample) The average SWLS scores for mothers $(F=155.02, p \leq .001)$ and fathers $(F=33.44, p \leq .001)$ in Profile 1 were significantly lower than Profile 2,3 and 5 . The average SWLS scores for adolescents in Profile 1 were significantly lower than Profile 2 and 3 ( $F=44.76, p \leq .001)$ (Fig. 1). Within this profile, children scored higher in SWLS $(p=.008)$ and SWFaL $(p=.038)$ than their mothers and fathers. No significant differences between family members were found in their SWFoL average scores $(p=.281)$. The average family APGAR scale average for mothers was significantly higher than for fathers and children $(p<.001)$. Mothers and fathers did not differ in their WLB average scores $(p=.483)$.

Latent Profile 2: Families with high life satisfaction (29.43\%) The average SWLS scores for mothers, fathers and adolescents in Profile 2 were significantly higher than Profiles 1 and 4 (Fig. 1). Within this profile, there were no significant differences between family members in their SWLS average scores $(p=.381)$. No significant differences between family members were found in their SWFoL $(p=.098)$ and SWFaL $(p=.655)$ average scores. The average family APGAR scale average for mothers was significantly higher than for fathers and children $(p<.001)$. Mothers and fathers did not differ in their WLB average scores $(p=.055)$.

Latent Profile 3: Families with high life satisfaction in parents and very high satisfaction in children (14.90\%) The average SWLS scores for mothers in Profile 3 were significantly lower than Profile 5. Fathers and children in Profile 3 had the highest average SWLS scores, although the SWLS scores from fathers did not differ from those in Profiles 2 and 5 (Fig. 1). Within this profile, children scored higher in

Table 2 Summary of latent class cluster models

\begin{tabular}{|c|c|c|c|c|c|c|}
\hline & LL & BIC(LL) & CAIC(LL) & Npar & Entropy & $\begin{array}{l}\text { Classification } \\
\text { Error }\end{array}$ \\
\hline 1-Cluster & -2567.59 & 5169.47 & 5175.47 & 3 & 1.00 & .00 \\
\hline 2-Cluster & -2439.86 & 4953.99 & 4966.99 & 13 & 0.90 & .06 \\
\hline 3-Cluster & -2384.43 & 4883.14 & 4903.14 & 20 & 0.96 & .09 \\
\hline 4-Cluster & -2333.31 & 4825.89 & 4859.35 & 27 & 0.72 & .10 \\
\hline 5-Cluster & -2315.54 & 4820.89 & 4847.89 & 34 & 0.85 & .15 \\
\hline 6-Cluster & -2298.43 & 4831.11 & 4872.11 & 41 & 0.78 & .16 \\
\hline 7-Cluster & 2257.40 & 4889.07 & 4887.07 & 48 & 0.77 & .16 \\
\hline
\end{tabular}

$\mathrm{LL}=\mathrm{Log}$-likelihood; $\mathrm{BIC}(\mathrm{LL})=$ Bayesian information criterion base on the $\log$-likelihood. CAIC $(\mathrm{LL})=$ Consistent Akaike's Information Criterion. Npar= Number of parameters 
SWLS $(p<.001)$, SWFoL $(p=.042)$, and SWFaL $(p=.007)$ than their mothers and fathers. The average family APGAR scale average for mothers was significantly higher than for fathers and children $(p<.001)$. Mothers in this profile also scored significantly higher than fathers in $\operatorname{WLB}(p=.028)$.

\section{Latent Profile 4: Families with relatively low life satisfaction} (13.77\%) Mothers, fathers and adolescents in Profile 4 had the lowest SWLS scores, significantly lower than the other profiles (Fig. 1). Within this profile, children scored higher in SWLS than their mothers and fathers $(p=.030)$. No significant differences between family members were found in their $\operatorname{SWFaL}(p=.377), \operatorname{SWFoL}(p=.262)$, and Family APGAR ( $p$ $=.158)$ average scores. Mothers and fathers did not differ in their WLB average scores $(p=.367)$.

Latent Profile 5: Families with very high life satisfaction in parents and medium life satisfaction in children (10.68\%) The average SWLS scores for mothers in Profile 5 were significantly higher than the rest of the profiles. The average SWLS scores for fathers in Profile 5 did not differ from Profiles 2 and 3. The average SWLS scores for adolescents in Profile 5 did not differ from Profiles 1, 2 and 4 (Fig. 1).
Within this last profile, mothers and fathers had a higher SWLS $(p<.001)$, SWFaL $(p=.006)$, and SWFoL $(p<$ $.001)$ scores than their children. The average family APGAR scale average for mothers was significantly higher than for fathers and children $(p<.001)$. Mothers and fathers did not differ in their WLB average scores $(p=.079)$.

Between families, the five profiles were also compared in terms of the following variables:

Satisfaction with food-related life (SWFoL, Answered by the Three Family Members) The average SWFoL scores for mothers and fathers $(p \leq .001)$ in Profile 5 were the highest, although they did not differ from Profile 3 . The lowest average SWFoL scores for mothers and fathers corresponded to Profile 4, although they did not differ from Profile 1. Adolescents in Profile 3 had the highest average scores on the SWFoL $(p<.001)$, although it did not differ from Profile 2 (Table 3).

Satisfaction with family life (SWFaL, Answered by the Three Family Members) The average SWFaL scores for mothers and fathers in Profile 5 were the highest $(p \leq .001)$, although they did not differ from Profile 3. The lowest average SWFaL

Table 3 Differences between the five profiles according to food-related life (SWFoL) and family life (SWFaL), family APGAR scores in mothers, fathers and adolescents, and work-life balance (WLB) in mothers and fathers

\begin{tabular}{|c|c|c|c|c|c|c|c|}
\hline & Profile 1 & Profile 2 & Profile 3 & Profile 4 & Profile 5 & $\mathrm{~F}$ & $P$ value \\
\hline Profile size $(\%)$ & 31.2 & 29.4 & 14.9 & 13.7 & 10.6 & & \\
\hline \multicolumn{8}{|l|}{ SWFoL } \\
\hline Mother $^{2}$ & $22.5 \mathrm{~cd}$ & $23.9 \mathrm{bc}$ & $24.8 \mathrm{ab}$ & $20.3 \mathrm{~d}$ & $26.9 \mathrm{a}$ & 12.120 & $<.001$ \\
\hline Father $^{2}$ & $23.2 \mathrm{~cd}$ & $24.6 \mathrm{bc}$ & $25.6 \mathrm{ab}$ & $21.2 \mathrm{~d}$ & $27.3 \mathrm{a}$ & 14.467 & $<.001$ \\
\hline Adolescent $^{1}$ & $23.5 \mathrm{~b}$ & $25.1 \mathrm{ab}$ & $27.0 \mathrm{a}$ & $22.3 \mathrm{~b}$ & $22.9 \mathrm{~b}$ & 8.326 & $<.001$ \\
\hline \multicolumn{8}{|l|}{$S W F a L$} \\
\hline Mother $^{1}$ & $23.6 \mathrm{c}$ & $25.7 \mathrm{~b}$ & $27.8 \mathrm{a}$ & $20.4 \mathrm{~d}$ & $28.3 \mathrm{a}$ & 27.802 & $<.001$ \\
\hline Father $^{1}$ & $24.3 \mathrm{c}$ & $25.9 \mathrm{~b}$ & $27.8 \mathrm{a}$ & $21.5 \mathrm{c}$ & $28.2 \mathrm{a}$ & 21.212 & $<.001$ \\
\hline Adolescent ${ }^{1}$ & $24.8 \mathrm{c}$ & $26.2 \mathrm{~b}$ & $29.2 \mathrm{a}$ & $22.4 \mathrm{c}$ & $25.1 \mathrm{bc}$ & 18.995 & $<.001$ \\
\hline \multicolumn{8}{|l|}{ Family APGAR } \\
\hline Mother $^{1}$ & $8.3 \mathrm{~b}$ & $8.8 \mathrm{a}$ & $8.9 \mathrm{a}$ & $6.8 \mathrm{c}$ & $9.3 \mathrm{a}$ & 15.961 & $<.001$ \\
\hline Father $^{1}$ & $6.5 \mathrm{~b}$ & $7.3 \mathrm{a}$ & $7.1 \mathrm{a}$ & $6.0 \mathrm{c}$ & $7.4 \mathrm{a}$ & 6.818 & $<.001$ \\
\hline Adolescent ${ }^{1}$ & $6.4 \mathrm{~b}$ & $7.0 \mathrm{a}$ & $7.2 \mathrm{a}$ & $6.0 \mathrm{~b}$ & $6.2 \mathrm{~b}$ & 4.937 & 0.001 \\
\hline \multicolumn{8}{|l|}{$W L B$} \\
\hline Mother $^{1}$ & $11.6 \mathrm{c}$ & $12.7 \mathrm{~b}$ & $13.7 \mathrm{a}$ & $11.0 \mathrm{c}$ & $14.4 \mathrm{a}$ & 21.277 & $<.001$ \\
\hline Father ${ }^{1}$ & $11.8 \mathrm{~cd}$ & $12.1 \mathrm{bc}$ & $12.9 \mathrm{ab}$ & $10.4 \mathrm{~d}$ & $13.7 \mathrm{a}$ & 11.936 & $<.001$ \\
\hline
\end{tabular}

\footnotetext{
${ }^{1}$ Different letters in the line indicate significant differences according to Dunnett's T3 multiple comparisons test

${ }^{2}$ Different letters in the line indicate significant differences according to Tukey multiple comparisons test

Profile 1: "Medium level of life satisfaction families"

Profile 2: "High level of life satisfaction families"

Profile 3: "High level of life satisfaction families with very high level of satisfaction children"

Profile 4: "Relatively low level of life satisfaction families"

Profile 5: "Very high level of life satisfaction parents with adolescents with medium level of life satisfaction"
} 
Table 4 Percentage of families in the five profiles by socioeconomic differences, i.e. family socioeconomic status and mothers' and fathers' perception of the current financial situation of the household

\begin{tabular}{|c|c|c|c|c|c|}
\hline & Profile 1 & Profile 2 & Profile 3 & Profile 4 & Profile 5 \\
\hline Socioeconomic status & & $p=.030$ & & & \\
\hline High and upper-middle & 7.7 & 10.5 & 13.7 & 2.8 & 30.0 \\
\hline Middle-Middle & 20.9 & 26.3 & 21.6 & 5.6 & 20.0 \\
\hline Lower-Middle & 35.2 & 36.8 & 39.2 & 47.2 & 26.7 \\
\hline Low & 24.2 & 21.1 & 17.6 & 30.6 & 10.0 \\
\hline Very low & 12.1 & 5.3 & 7.8 & 13.9 & 13.3 \\
\hline Mother Current financial situation of the household & $p<.001$ & & & & \\
\hline Very difficult & 13.2 & 4.2 & 2.0 & 11.1 & 3.3 \\
\hline Difficult & 25.3 & 18.9 & 21.6 & 41.7 & 13.3 \\
\hline Regular & 48.0 & 55.8 & 39.2 & 33.3 & 33.3 \\
\hline Good & 13.2 & 18.9 & 29.4 & 11.1 & 46.7 \\
\hline Very Good & 0.4 & 2.1 & 7.8 & 2.8 & 3.3 \\
\hline Father Current financial situation of the household & $p<.001$ & & & & \\
\hline Very difficult & 11.0 & 2.1 & 3.9 & 13.9 & 3.3 \\
\hline Difficult & 28.6 & 20.0 & 19.6 & 44.4 & 16.7 \\
\hline Regular & 47.0 & 52.6 & 35.3 & 30.6 & 36.7 \\
\hline Good & 13.0 & 24.2 & 33.3 & 5.6 & 40.0 \\
\hline Very Good & 0.5 & 1.1 & 7.8 & 5.6 & 3.3 \\
\hline
\end{tabular}

$\mathrm{P}$ value corresponds to the (bilateral) asymptotic significance obtained in Pearson's Chi-squared test

Profile 1: "Medium level of life satisfaction families"

Profile 2: "High level of life satisfaction families"

Profile 3: "High level of life satisfaction families with very high level of satisfaction children"

Profile 4: "Relatively low level of life satisfaction families"

Profile 5: "Very high level of life satisfaction parents with adolescents with medium level of life satisfaction"

scores for mothers, fathers and adolescents $(p \leq .001)$ corresponded to Profile 4, although the fathers' scores did not differ from those in Profile 1, and the adolescents' scores did not differ from their counterparts in Profiles 1 and 5. Adolescents in Profile 3 had significantly higher average SWFaL scores than the rest of the profiles (Table 3).

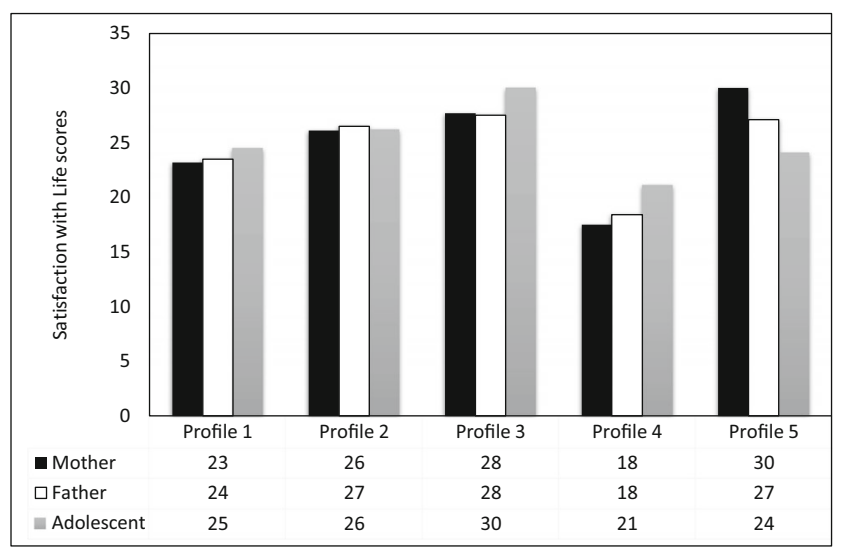

Fig. 1 Family profiles based on life satisfaction in dual-earner parents with adolescent children. Scores for the Satisfaction with Life Scale were subjected to Dunnett's T3 multiple comparisons test
Family APGAR (Answered by the Three Family Members) The average family APGAR scores for mothers and fathers in Profile 5 were the highest $(p \leq .001)$, although their scores did not differ from Profiles 2 and 3. Adolescents in Profile 3 had the highest average family APGAR score, although it did not differ from that of Profile 2. The lowest average Family APGAR scores for mothers, fathers and adolescents $(p \leq .05)$ corresponded to Profile 4, although adolescents' scores did not differ from Profiles 1 and 5 (Table 3).

Work-life balance (WLB, Answered by Parents) The average WLB scores for mothers and fathers in Profile 5 were the highest $(p \leq .001)$, although they did not differ from Profile 3. The lowest average WLB scores for mothers and fathers corresponded to Profile 4, although they did not significantly differ from those of parents in Profile 1 (Table 3 ).

Perception of financial situation (answered by mothers and fathers) and socioeconomic status (SES, determined by occupation and level of education of the head of household as reported by mothers, Table 4). Profile 1 had a higher proportion of families in which the mothers perceived their current financial situation as very difficult $(p \leq .001)$. Profile 2 had a greater 
proportion of mothers who perceived it as regular. Profile $3 \mathrm{had}$ a higher presence of mothers who reported a very good perception and higher proportion of fathers who had a good or a very good perception $(p \leq .001)$. Profile 4 had higher proportions of mothers and fathers who perceived their financial situation as difficult, while Profile 5 had greater proportions of mothers and fathers who perceived a good financial situation. Profile 5 was composed of a greater proportion of families belonging to the high and upper-middle SES $(p \leq .050)$.

No significant differences between the profiles were found in the rest of the variables included in this study $(p>.100)$.

\section{Balance in Life Satisfaction Levels among Family Members}

The last set of analysis examined differences between families with balanced and imbalanced life satisfaction among its three members (i.e. their life satisfaction levels were similar or differing, respectively). Overall, families with high balance in their life satisfaction scored higher in other satisfaction measures (i.e. family life, food-related life) and in family functioning than imbalanced families.

Table 5 shows a comparison between very balanced (1st quartile of life satisfaction balance, $n=68$ ) and very imbalanced (4th quartile of life satisfaction balance, $n=91$ ) families. Mothers, fathers and children from very balanced families had significantly higher SWLS average scores than those from very imbalanced families $(p \leq .001)$. In terms of SWFoL, only mothers and children from very balanced families had significantly higher average scores than mothers and children from very imbalanced families $(p \leq .050)$. For SWFaL, mothers $(p \leq .001)$, fathers and children $(p \leq .05)$ from very balanced families had significantly higher average scores than those from very imbalanced families $(p \leq .001)$. For the family APGAR scores, mothers $(p \leq .001)$ and children $(p \leq .050)$ from very balanced families had significantly higher scores in this measure than their counterparts from very imbalanced families.

Lastly, comparisons between these two types of families on the perception of their current financial situation are displayed on Table 6. Very imbalanced families had a greater proportion of mothers and fathers who perceived their financial situation as very difficult or difficult. In balanced families, there was a greater proportion of fathers who perceived a good financial situation for their household $(\mathrm{p} \leq .050)$.

No significant differences between the very balanced and very imbalanced families were found in the rest of the variables included in this study $(p>.100)$.

\section{Discussion}

The aim of this study was to identify family profiles based on the levels of life satisfaction, and to characterize them using associated variables from the family, food, and work domains, in a sample of mothers, fathers and adolescents in dual-earner families. Our results showed that life satisfaction is heterogeneous among these families, and it is also heterogeneous between parents and their children. These profiles also differed in the levels of satisfaction with family life and food-related life, and family functioning between families, parents' WLB and perception of household financial situation. Levels of these variables also differed between the members within family profiles.
Table 5 Differences between balanced and imbalanced families according to satisfaction with life (SWLS), food-related life (SWFoL) and family life (SWFaL), and family functioning (Family APGAR) scores ${ }^{1}$

\begin{tabular}{|c|c|c|c|c|}
\hline & $\begin{array}{l}\text { Very balanced } \\
\text { families }(n=68)\end{array}$ & $\begin{array}{l}\text { Very imbalanced } \\
\text { families }(n=91)\end{array}$ & $\mathrm{t}$ & $\mathrm{P}$ value \\
\hline \multicolumn{5}{|l|}{ SWLS } \\
\hline Mother & 26.2 & 22.2 & 5.75 & $<.001$ \\
\hline Father & 26.2 & 23.5 & 3.41 & 0.001 \\
\hline Adolescent & 26.3 & 23.1 & 3.96 & $<.001$ \\
\hline \multicolumn{5}{|l|}{$S W F o L$} \\
\hline Mother & 24.6 & 22.9 & 2.22 & .028 \\
\hline Adolescent & 25.4 & 22.9 & 3.04 & .003 \\
\hline \multicolumn{5}{|l|}{$S W F a L$} \\
\hline Mother & 26.3 & 23.0 & 4.66 & $<.001$ \\
\hline Father & 26.2 & 24.4 & 2.43 & .017 \\
\hline Adolescent & 26.2 & 23.7 & 3.15 & .002 \\
\hline \multicolumn{5}{|c|}{ Family APGAR } \\
\hline Mother & 8.9 & 7.7 & 4.19 & $<.001$ \\
\hline Adolescent & 6.9 & 6.0 & 3.02 & .003 \\
\hline
\end{tabular}

${ }^{1}$ Variables not shown in this table do not significantly differ from these family groups 
Table 6 Percentage of the perceived current financial situation of the household reported by mothers and fathers in very balanced and very imbalanced families

\begin{tabular}{lll}
\hline & $\begin{array}{l}\text { Very balanced } \\
\text { families }(\mathrm{n}=68)\end{array}$ & $\begin{array}{l}\text { Very imbalanced } \\
\text { families (n=91) }\end{array}$ \\
\hline Mother Current financial situation of the household & $p=.031$ & 11.8 \\
Very difficult & 3.3 & 32.4 \\
Difficult & 18.7 & 42.6 \\
Regular & 52.7 & 11.8 \\
Good & 22.0 & 1.5 \\
Very Good & 3.3 & 13.2 \\
Father Current financial situation of the household & $p=.002$ & 38.2 \\
Very difficult & 3.3 & 36.8 \\
Difficult & 19.8 & 8.8 \\
Regular & 48.4 & 2.9 \\
Good & 24.2 & 4.4 \\
Very Good & & \\
\hline
\end{tabular}

$\mathrm{P}$ value corresponds to the (bilateral) asymptotic significance obtained in Pearson's Chi-squared test
The first objective of this study was to identify family profiles based on the level of life satisfaction of working mothers and fathers and their adolescent children. These profiles were established using Latent Profile Analysis (LPA), which entails a departure from more traditional approaches that test links from overall life satisfaction to different domains. The LPA allowed to examine the heterogeneity of life satisfaction between families; these distinctions cannot be detected by establishing associations between variables. With this analysis, five family profiles were found: Profile 1, Families with medium life satisfaction (31.22\%); Profile 2, Families with high life satisfaction (29.43\%); Profile 3, Families with high life satisfaction in parents and very high satisfaction in children (14.90\%); Profile 4, Families with relatively low life satisfaction (13.77\%); and Profile 5, Families with very high life satisfaction in parents and medium life satisfaction in children (10.68\%).

The literature reports that life satisfaction levels tend to be similar among members of the same family (Headey et al., 2014; Ma, 2016), but this expectation was met only in the family Profile 2 . The other four profiles aligned with the opposite proposition, that is, family members differed in their levels of life satisfaction (Casas et al., 2012), with adolescents displaying higher levels of life satisfaction than their parents (Profiles 1, 3 and 4) or vice versa (Profile 5). Homogenous levels of life satisfaction within a family are expected based on several factors, including the transmission of values and behavioral choices from parents to their children (Headey et al., 2014). Subsequent objectives in this study sought to examine variables that may help explain heterogeneous levels of life satisfaction.

The second and third objectives of this study were to examine between-family and within-family differences, respectively, to test whether family profiles differed also in terms of variables related to the family, food, and work domains. Results are consistent with previous studies that suggest that satisfaction in specific domains is not homogenous between families (Schnettler, Grunert, et al., 2018a, b; Schnettler, Lobos, et al., 2017a; Vieira et al., 2018). However, it should be noted that in some family profiles (Profiles 2 and 4) the three family members had similar levels of satisfaction with family life and food-related life. In other types of families (Profile 3 ) children had higher family life and food-related life satisfaction than their parents, while in other families, children had only higher levels of satisfaction with family life than their parents (Profile 1). In the remaining families, the parents' satisfaction with family and food-related life is higher than their children's (Profile 5). These differences are further discussed below.

Profile analysis also suggested various trends within families. Only in Profile 2 the three members showed similar (high) life satisfaction levels, and showed similar levels of SWFaL and SWFoL. The similarities between levels of life and domain satisfaction in these family profiles recall the interdependence between family members posited by Family Systems Theory (Kerr \& Bowen, 1988).

The four remaining profiles question this interdependence within families although to a different extent. In Profile 4 (low life satisfaction), children had higher life satisfaction levels than their parents, but the three family members showed similar levels of SWFaL and SWFoL. In Profile 1 (medium life satisfaction), children had higher levels of life and family life satisfaction levels than their parents, but the three family members showed similar levels of SWFoL. Profiles 3 and 5, in which life satisfaction levels differed between parents and children, also showed divergent levels of associated variables. Children in Profile 3, with high life satisfaction in parents and very high in children, reported higher SWFaL and SWFoL 
than their parents. In these families, satisfaction levels were consistent within the same individual but not between other family members. Lastly, parents in Profile 5 had very high life satisfaction, while their children reported a medium level. Parents in this profile also reported higher SWFaL and SWFoL than their children.

In each profile, family functioning reported by each family member followed similar patterns to their reported levels of satisfaction with life and family life. These results support findings that have associated family functioning with life satisfaction (Jia et al., 2018), and with family life satisfaction (Botha et al., 2018). Family functioning and food-related life satisfaction levels also followed similar patterns; both of these variables have been separately linked in past research to family cohesion (Alderfer et al., 2007; Schnettler, Grunert, et al., 2018a, b; Schnettler, Lobos, et al., 2017a), which may be an underlying mechanism in the association between satisfaction with food-related life and the family domain. However, it is noteworthy that parents in Profile 5 also reported higher family functioning than their children. Profile 5 children's family functioning scores, in turn, were more similar to those children in families with medium (Profile 1) and low (Profile 4) life satisfaction.

Family profiles also differed in terms of the parents' worklife balance. Within families, the parents' WLB scores in the five family profiles were also associated with their levels of life and family life satisfaction. This finding is in line with research showing a positive relationship between WLB and family life satisfaction in employees (Brough et al., 2014; Ferguson, Carlson, Zivnuska, \& Whitten, 2012) and their partners (Ferguson et al., 2012). However, there were no significant differences between mothers and fathers within most of the profiles, which contradicts findings reported by Vieira et al. (2018) and Tammelin et al. (2017) in European countries regarding gender differences in work-family conflict within dual-earner couples.

Gender differences were expected in this study based on the evidence showing that women carry greater parental pressures (Thomas et al., 2017), as well as the patriarchal nature of South American societies (Terrazas-Carrillo et al., 2016) from which the sample was drawn. The lack of gender differences in work-life balance levels may reflect either a practical need for more flexible gender roles in dual-earner couples, or a greater cultural shift in the traditional family structure predominating in South American countries, at least for families in which both mother and father are employed and have children in the adolescent stage. A third possibility is that, as in Latin America it is expected that women with a paid job remain primarily responsible for domestic work and childrearing, women adjust to, and try to meet these expectations. Hence, they may perceive that they can balance these and the rest of their life demands properly, and thus their work-life balance levels do not differ from those of their male partners.
In other words, the different adjustments that mothers and fathers make to cultural gender expectations may result in a similar outcome. Based on these possibilities, these family profiles support evidence of the positive association between WLB and life satisfaction in employees of both genders (Greenhaus \& Powell, 2006; Haar, 2013; Haar et al., 2014; Schnettler et al., 2020).

Higher levels of WLB in both parents were also associated with greater life and family life satisfaction in their children in most of the family profiles. This was an expected finding for mothers. Previous studies have shown that positive workrelated experiences in mothers are positively related to their children's life satisfaction (Mauno et al., 2018), and that mothers' WLB is positively linked to the adolescents' SWFaL (Schnettler, Miranda-Zapata, et al., 2018). These relations are better observed in Profile 3 , in which mothers had a significantly higher WLB than fathers. Children in this profile also reported higher levels of life, family life and food-related life satisfaction than children in the other four profiles, supporting the literature that highlights the importance of the mothers' WLB on their children's well-being (Schnettler, Miranda-Zapata, et al., 2018).

The influence of fathers' WLB on their children's wellbeing have been less reported, but our findings suggest that fathers' WLB also contributes to the adolescents' life and family life satisfaction. Vieira et al. (2016) found that greater work-family conflict was highly associated with inadequate parenting practices. This latter study, however, was conducted in dual-earner parents with younger children, who demand more attention and time from their parents than adolescents (Thomas et al., 2017). In positive terms, the father-child associations found in this study may suggest that a more balanced relationship between work and other life roles might be related to higher parental involvement and lower parent-child relational frustration, which may be associated with the child's life and family life satisfaction. More research is needed, however, to corroborate the relationship between fathers' WLB and their adolescent children's well-being.

The resulting family profiles also showed that a better WLB in parents is linked to their children's SWFoL. It may be the case that parents who experience a better WLB are able to conduct food-related behaviors that have a positive impact on their children, such as having more frequent family meals (Nepper \& Chai, 2016; Sharif et al., 2017), which in turn has been related to a greater SWFoL (Schnettler, Grunert, et al., 2018a, b; Schnettler, Lobos, et al., 2017a). The positive association between both parents' WLB and the adolescents' SWFoL in most of the family profiles partially support previous findings (Schnettler, Miranda-Zapata, et al., 2018), but Profile 5 shows a different situation.

Higher levels of WLB in Profile 5 parents were not related to their children's life satisfaction, SWFaL nor SWFoL. However, Profile 5 children presented similar scores in these 
three variables as did children in Profiles 1 and 4, whose parents had the lowest WLB scores. Hence, WLB in parents tends to be related to their children's satisfaction, overall and in the family and food domains, but this is not the case for all families. WLB entails a person's perceived allocation of time and energy to work and to other life roles. It can be hypothesized that parents in Profile 5 consider that they have adequately assigned their individual resources (e.g.: time, attention) to their work and other life roles, but resources for their parental role may be insufficient to fulfill their children's needs. These reduced resources may in turn be associated to children's less positive assessment of their own life and domains. Alternative explanations for these discrepancies between parents and children in Profile 5 are that these children may be more independent from their parents, or that caregiving from their parents is perceived as a stressor rather than as a facilitator of life satisfaction (Thomas et al., 2017).

Family profiles also differed in their socioeconomic status (SES). There is substantial evidence that socioeconomic disadvantages put additional pressures on families (Thomas et al., 2017), and studies in developed countries show that financial instability influences parents' life satisfaction, and the adolescents' well-being (Conger \& Conger, 2008; Pollmann-Schult, 2014; Rajani et al., 2019). Contrary to these expectations, the family profiles do not suggest a relation between SES and parents and their children's life satisfaction (Dobewall et al., 2019; Ma, 2016), SWFaL (Botha et al., 2018) nor SWFoL (Schnettler, Grunert, et al., 2018a, b). These findings may be supported by a previous study suggesting that social capital can trump material well-being in terms of importance for life satisfaction in Latin American individuals (Ateca-Amestoy, Aguilar, \& Moro-Egido, 2013). Moreover, in a sample of low-income Chilean adults, Hernández, Muñoz, and Moyano-Díaz (2017) found that social relationships, particularly family, were part of the meaning of happiness, the affective component of subjective well-being; a material dimension, "to have", was also present in this meaning, but it referred to having the basic life elements, such as work, health, and family. In this study, only Profile 5, with a higher proportion of families belonging to the high and upper-middle SES, aligned with the expectation of higher well-being in general and in the food and family domains, but this was found only in the parents, not in their children. Besides accounting for the family-oriented aspects of Latin American culture to explain a lack of relation between SES and life satisfaction, the confounding effect of SES itself should be assessed in future research. As Hernández et al. (2017) showed, low-income and high-income individuals may report similar levels of happiness, but define it from a different position in the hierarchy of needs (i.e. "basic life elements" for low-income individuals, and self-realization for high-income ones).
Family profiles also differed in the parents' perception of the financial situation of the household. It was found that families with low (Profile 3) or medium (Profile 1) life satisfaction also reported a perception of, respectively, a difficult or very difficult household financial situation. This result aligns with reports of an association between a poor family economic situation and work-family conflict in dual-earner couples in the EU (Tammelin et al., 2017). Moreover, differences between profiles in the perception of household financial situation were observed in mothers more significantly than in fathers. It was expected that fathers would present more significant differences in this perception, as the literature shows that the stress due to the family's financial situation is more marked in men, given their traditional role as the family's "breadwinner" (Pollmann-Schult, 2014). In this study, however, both mother and father have a paid job and thus both may share the responsibility for financial issues of the family. It can then be hypothesized that this distinct perception in mothers is due to women being more sensitive than men to the family's financial strains. It may also be the case that handling household finances are considered an extension of the expected responsibilities of women in the domestic spheres, regardless of their work role.

Nevertheless, the three family members in profiles with greater concerns about the financial situation of the household (Profiles 1 and 4) also showed lower levels of SWFaL and SWFoL. Financial strains may lead to a decrease on parents' satisfaction with family life and with food-related life because insufficient economic resources can keep them from providing food and other goods to their family (Schnettler, Grunert, et al., 2018a, b). This scarcity, in turn, may negatively influence the adolescents' satisfaction in the food and family domains. Moreover, financial hardships also negatively influence parent-child interactions (Conger \& Conger, 2008). It has been shown that financial strains exacerbate family stress (Botha et al., 2018), which may affect family relationships in general, and those associated with the social dimension of food in particular (Sharif et al., 2017). In this regard, findings from this study suggest that perception of financial difficulties is associated with overall life satisfaction, as well as with satisfaction in specific domains.

The fourth and last objective of this study was to compare families whose three members had similar levels of life satisfaction (i.e. balanced families), with those who had different levels (i.e. imbalanced families). Families on both extremes of life satisfaction balance were compared and five variables showed differences in this regard. The first two differing variables were life satisfaction and satisfaction with family life. The higher levels of life satisfaction in the three family members of the balanced families, compared to those in the imbalanced families, align with previous findings (Szcześniak \& Tułecka, 2020; Turkdogan et al., 2019) based on the Circumplex Model of Marital and Family Systems (Olson, 
2000; Olson et al., 2019). Likewise, there were higher levels of satisfaction with family life in the three family members belonging to the balanced families. This latter finding is in line with studies that have stressed the importance of family relationships and satisfaction with family life for well-being in adults and adolescents (Castellá, Casas, Ramos, Bedin, \& González, 2018; Lawler, Newland, Giger, Roh, \& Brockevelt, 2017; Schnettler, Miranda-Zapata, et al., 2018). Therefore, it can be suggested that family life satisfaction in all family members must be promoted to achieve balanced families in terms of life satisfaction.

The third variable was the perception of the household financial situation: Perception of a difficult financial situation was associated with lower life satisfaction balance; this finding was expected based on the explanation presented in the previous paragraph. The two other variables in which differences were found between balanced and imbalanced families were SWFoL and family functioning, and only between mothers and adolescents. The mother-child differences in both variables for balanced and imbalanced families may be related to the higher importance attributed to the mother-child relationship than the father-child one. Mothers who work outside the home are still considered primarily responsible for raising (Dobewall et al., 2019; Matias et al., 2017a, b) and feeding (Sharif et al., 2017) their children, and tend to spend more time with their children than the father. For family functioning, Kinkead, Saracostti, Grau, and Caro (2017) reported that adolescents assess that their mothers have a more important participation than their fathers in terms of emotional care and expressions of affection. For SWFoL, research has found a higher association in this variable between mothers and children than between fathers and children (Schnettler, Lobos, et al., 2017a). It can be thus suggested that the mother's and the adolescent child's perception of family functioning and SWFoL play an important role in achieving balance in terms of the family members' life satisfaction. The fathers' role here is unclear and should be addressed in future research, but it can be hypothesized that mother's and child's perception of family functioning and SWFoL cross over to the father, and become more relevant than his own experience in these domains to achieve overall life satisfaction.

Balanced and imbalanced families did not differ in terms of parents' WLB. The resulting family profiles suggested that the contrary may be the case. The two profiles with highest WLB were those with high (Profile 3) and very high (Profile 5) life satisfaction in mothers and fathers; lowest WLB scores were found in profiles with medium (Profile 1) and low (Profile 4) life satisfaction. However, children from Profiles 3 and 5 differed from their parents' life satisfaction levels, scoring either higher (Profile 3) or lower (Profile 5) than them. Contrary to this WLB - life satisfaction imbalance trend seen in these profiles, comparisons between balanced and imbalanced families suggest that parents' higher balance between work and life roles can be independent from life satisfaction in children. Adolescents may focus on their own increasingly demanding life roles (e.g. at school) and thus distance themselves from those of their parents', while they can also recognize their parent's efforts on behalf of family well-being, even if these entail parental absence due to work-related reasons (Kinkead et al., 2017).

The limitations of this study should be addressed to improve future research. The main limitations of this study are its cross-sectional design, and the non-probabilistic nature of the sample and its relatively small size. A second limitation is that all data were self-reported, and some responses may have been affected by social desirability. In addition, we did not ask about the parents' type of employment nor the number of working hours, so it was not possible to associate parents' WLB with their job conditions. These variables should be taken into account in future studies given that they may moderate the levels of WLB in working parents (Matias et al., 2017a, b). Lastly, we did not assess other family-related variables such as family support, parents' and children's mental health and marital satisfaction. Future studies should assess the relationships between these variables and family members' well-being.

Despite these limitations, this study contributes to further exploring the heterogeneity of life satisfaction in dual-earner families with adolescents. Our results provide new insights into relationships between family, food, work, and life satisfaction in a South American country. Previous studies focusing on life satisfaction among members of a family, or on the balance between work and family domains, have been conducted mostly in USA, Asia, and Europe (Headey et al., 2014; Liu \& Cheung, 2015; Pollmann-Schult, 2014; TerrazasCarrillo et al., 2016). Differences between South American families still uphold strong patriarchal expectations: While women's participation in the work force has increased in recent decades, this has not entailed any changes on women's (nor on men's) share of family work and childcare (TerrazasCarrillo et al., 2016). The differences seen by gender and in different members in these families suggest new directions for research, and eventually for interventions and policies, that focus on improving family life conditions that can have an impact on life satisfaction.

\section{Implications for Research and Policymaking}

These results have implications for research and family interventions and policymaking. Researchers should further investigate the discrepancies found in this study compared to previous research, such as work-life balance by gender and the relation between SES and life satisfaction. Studies should also examine family profiles whose members show discrepancies in their life satisfaction and domain satisfaction levels, such as those in Profile 5, in which parents' well-being indicators (e. 
g. life satisfaction, work-life balance) do not seem to cross over to their children's well-being. Lastly, the diverse components involved in enhancing life satisfaction, and the different family profiles detected in this regard, suggest that practitioners and policymakers from different areas (e.g. organizational, health and nutrition, and school domains) must work together in the creation of guidelines and policies that promote individual and family well-being, accounting for families with distinct characteristics and needs.

Author Contributions B.Sch. conceived and wrote the first manuscript draft, approved the statistical analysis and the final version of the manuscript. E.M.-Z. guided the statistical analysis. L.O. and C.H., supervised data collection and made a critical analysis of the final version of the manuscript. K.G., G.L., and M.L. made a critical analysis of the final version of the manuscript. H. M. conducted statistical analysis requested for the revised version of the manuscript. All authors read and approved the final manuscript.

Funding This study was funded by Fondecyt Project $n^{\circ} 1160005$, Fondecyt Project $n^{\circ} 1190017$ and partially by the Dirección de Investigación, Universidad de La Frontera.

Data Availability The datasets generated during and/or analysed during the current study are available from the corresponding author on reasonable request.

\section{Compliance with Ethical Standards}

Conflict of Interest On behalf of all authors, the corresponding author states that there is no conflict of interest.

Open Access This article is licensed under a Creative Commons Attribution 4.0 International License, which permits use, sharing, adaptation, distribution and reproduction in any medium or format, as long as you give appropriate credit to the original author(s) and the source, provide a link to the Creative Commons licence, and indicate if changes were made. The images or other third party material in this article are included in the article's Creative Commons licence, unless indicated otherwise in a credit line to the material. If material is not included in the article's Creative Commons licence and your intended use is not permitted by statutory regulation or exceeds the permitted use, you will need to obtain permission directly from the copyright holder. To view a copy of this licence, visit http://creativecommons.org/licenses/by/4.0/.

\section{References}

Adimark (2004). Mapa Socioeconómico de Chile. http://www.adimark. cl. Accessed 30 December 2015.

Alderfer, M. A., Fiese, B. H., Gold, J. I., Cutuli, J. J., Holmbeck, G. N., Goldbeck, L., et al. (2007). Evidence-based assessment in pediatric psychology: Family measures. Journal of Pediatric Psychology, 33(9), 1046-1061. https://doi.org/10.1093/jpepsy/jsm083.

Arita, B. (2005). Satisfacción por la vida y teoría homeostática del bienestar. Psicología y Salud, 15(1), 121-126. https://doi.org/10. 25009/pys.v15i1.826.

Ateca-Amestoy, V., Aguilar, A. C., \& Moro-Egido, A. I. (2013). Social interactions and life satisfaction: Evidence from Latin America.
Journal of Happiness Studies, 15(3), 527-554. https://doi.org/10. 1007/s10902-013-9434-y.

Augustijn, L. (2020). The intergenerational transmission of psychological well-being-evidence from the German socio-economic panel study (SOEP). Journal of Family Studies, 1-17. https://doi.org/10.1080/ 13229400.2020 .1741427$.

Bakker, A. B., \& Demerouti, E. (2013). The spillover-crossover model. In J. G. Grzywacz \& E. Demerouti (Eds.), Current issues in work and organizational psychology. New frontiers in work and family research (pp. 55-70). New York, NY, US: Psychology Press.

Bartley, S., Blanton, P., \& Gilliard, J. (2005). Husbands and wives in dual-earner marriages: Decision-making, gender role attitudes, division of household labor, and equity. Marriage \& Family Review, 37(4), 69-94. https://doi.org/10.1300/J002v37n04_05.

Bedin, L. M., \& Sarriera, J. C. (2014). Dyadic analysis of parent-children subjective well-being. Child Indicators Research, 7(3), 613-631. https://doi.org/10.1007/978-90-481-3377-22.

Bellón, J. A., Delgado, A., Luna, J. D. D., \& Lardelli, P. (1996). Validezy fiabilidad del cuestionario de función familiar Apgar-familiar. Atención Primaria, 18(6), 289-296.

Benítez, I., Pino, O., Padilla, J. L., \& Cuevas-Parra, A. (2016). Integrating scale data and patient perspectives for assessing functionality in schizophrenia. Community Mental Health Journal, 52(8), 914920. https://doi.org/10.1007/s10597-015-9959-0.

Botha, F., Booysen, F., \& Wouters, E. (2018). Satisfaction with family life in South Africa: The role of socioeconomic status. Journal of Happiness Studies, 19(8), 2339-2372. https://doi.org/10.1007/ s10902-017-9929-z.

Bourdier, L., Morvan, Y., Kotbagi, G., Kern, L., Romo, L., \& Berthoz, S. (2018). Examination of emotion-induced changes in eating: A latent profile analysis of the emotional appetite questionnaire. Appetite, 123, 72-81. https://doi.org/10.1016/j.appet.2017.11.108.

Brough, P., Timms, C., O'Driscoll, M. P., Kalliath, T., Siu, O. L., Sit, C., \& Lo, D. (2014). Work-life balance: A longitudinal evaluation of a new measure across Australia and New Zealand workers. The International Journal of Human Resource Management, 25(19), 2724-2744. https://doi.org/10.1080/09585192.2014.899262.

Carlsson, F., Lampi, E., Li, W., \& Martinsson, P. (2014). Subjective wellbeing among preadolescents and their parents - evidence of intergenerational transmission of well-being from urban China. The Journal of Socio-Economics, 48, 11-18. https://doi.org/10.1016/j. socec.2013.10.003.

Casas, F., Coenders, G., Gonzáles, M., Malo, S., Bertran, I., \& Figuer, C. (2012). Testing the relationship between parents' and their children's subjective well being. Journal of Happiness Studies, 13, 1031-1051. https://doi.org/10.1007/s11205-011-9781-1.

Castellá, J., Casas, F., Ramos, B., Bedin, L., \& González, M. (2018). Subjective well-being and personal relationships in childhood: Comparison of Brazilian and Spanish children. Interpersona: An International Journal on Personal Relationships, 12(1), 91-106. https://doi.org/10.5964/ijpr.v12i1.284.

Chi, P., Du, H., King, R. B., Zhou, N., Cao, H., \& Lin, X. (2019). Wellbeing contagion in the family: Transmission of happiness and distress between parents and children. Child Indicators Research, 12(6), 2189-2202. https://doi.org/10.1007/s12187-019-09636-4.

Conger, R. D., \& Conger, K. J. (2008). Understanding the processes through which economic hardship influences families and children. Handbook of Families and Poverty, 5, 64-78. https://doi.org/10. 1037/fam0000168.

Davis, K., Lawson, K., Almeida, D., Kelly, E., King, R., Hammer, L., Casper, L., Okechukwu, C., Hanson, G., \& McHale, S. (2015). Parents' daily time with their children: A workplace intervention. Pediatrics, 135(5), 875-882. https://doi.org/10.1542/peds.20142057.

Davis, A. N., Rudy, D., Su-Russell, C., \& Zhang, C. (2018). Chinese and European American undergraduates' perceptions of maternal 
warmth and negativity as predictors of self-esteem and life satisfaction. Cross-Cultural Research, 52(2), 192-212. https://doi.org/10. 1177/1069397117718812.

Diener, E., \& Biswas-Diener, R. (2000). New directions in subjective well-being research: The cutting edge. In E. Diener (Ed.), Positive psychology. Available on line at http://stat.psych.uiuc.edu/*ediener/ hottopic/NEW_DIRECTIONS.htlm (Accessed October 13, 2008).

Diener, E., Emmons, R., Larsen, R., \& Griffin, S. (1985). The satisfaction with life scale. Journal of Personality Assessment, 49, 71-75. https://doi.org/10.1207/s15327752jpa4901_13.

Dobewall, H., Hintsanen, M., Savelieva, K., Hakulinen, C., Merjonen, P., Gluschkoff, K., \& Keltikangas-Järvinen, L. (2019). Intergenerational transmission of latent satisfaction reflected by satisfaction across multiple life domains: A prospective 32-year follow-up study. Journal of Happiness Studies, 20(3), 955-970. https://doi.org/10.1007/s10902-018-9975-1.

Ferguson, M., Carlson, D. S., Zivnuska, S., \& Whitten, D. (2012). Support at work and home: The path to satisfaction through balance. Journal of Vocational Behavior, 80(2), 299-307. https://doi.org/10. 1016/j.jvb.2012.01.001.

Gómez, F. J., \& Ponce, E. R. (2010). Una nueva propuesta para la interpretación de Family apgar (versión en español). Atención Familiar, 17(4), 102-106. https://doi.org/10.22201/facmed. 14058871p.2010.4.21348.

Greenhaus, J. H., \& Powell, G. N. (2006). When work and family are allies: A theory of work-family enrichment. The Academy of Management Review, 31(1), 72-92. https://doi.org/10.5465/amr. 2006.19379625.

Grunert, K. G., Dean, M., Raats, M. M., Nielsen, N. A., \& Lumbers, M. (2007). A measure of satisfaction with food-related life. Appetite, 49(2), 486-493. https://doi.org/10.1016/j.appet.2007.03.010.

Haar, J. M. (2013). Testing a new measure of work-life balance: A study of parent and non-parent employees from New Zealand. The International Journal of Human Resource Management, 24(17), 3305-3324

Haar, J. M., Russo, M., Suñe, A., \& Ollier-Malaterre, A. (2014). Outcomes of work-life balance on job satisfaction, life satisfaction and mental health: A study across seven cultures. Journal of Vocational Behavior, 85(3), 361-373. https://doi.org/10.1016/j. jvb.2014.08.010

Headey, B., Muffels, R., \& Wagner, G. G. (2014). Parents transmit happiness along with associated values and behaviors to their children: A lifelong happiness dividend? Social Indicators Research, 116(3), 909-933. https://doi.org/10.2139/ssrn.2166753.

Hernández, K., Muñoz, M., \& Moyano-Díaz, E. (2017). Concept of happiness in adults from low-income class. Paidéia, 27, 386-394. https://doi.org/10.1590/1982-432727s1201703.

Jia, Z. H. O. U., Fang, H. U., Jing, W. U., Zou, Z. Y., Wang, Y. X., Peng, H. C., et al. (2018). Subjective well-being and family functioning among adolescents left behind by migrating parents in Jiangxi Province, China. Biomedical and Environmental Sciences, 31(5), 382-388. https://doi.org/10.3967/bes2018.049.

Kerr, M. E., \& Bowen, M. (1988). Family evaluation. New York: W.W. Norton.

Kinkead, A., Saracostti, M., Grau, M. O., \& Caro, P. (2017). Chilean children's perspectives on their parents' work and family conflicts, tensions, and reconciliations: Preliminary gender analysis. Child Indicators Research, 10(3), 649-672. https://doi.org/10.1007/ s12187-016-9388-9.

Lawler, M. J., Newland, L. A., Giger, J. T., Roh, S., \& Brockevelt, B. L. (2017). Ecological, relationship-based model of children's subjective well-being: Perspectives of 10 -year-old children in the United
States and 10 other countries. Child Indicators Research, 10(1), 118. https://doi.org/10.1007/s12187-016-9376-0.

Liu, H., \& Cheung, F. (2015). Testing crossover effects in an actorpartner interdependence model among Chinese dual-earner couples. International Journal of Psychology, 50(2), 106-114. https://doi. org/10.1002/ijop.12070.

Luebbe, A. M., Fussner, L. M., Kiel, E. J., Early, M. C., \& Bell, D. J. (2013). Role of adolescent and maternal depressive symptoms on transactional emotion recognition: Context and state affect matter. Emotion, 13, 1160-1172. https://doi.org/10.1037/a0033923.

Ma, K. R. (2016). Intergenerational transmission of wealth and life satisfaction. Applied Research in Quality of Life, 11(4), 1287-1308. https://doi.org/10.1007/s11482-015-9437-4.

Maftei, A., Holman, A. C., \& Cârlig, E. R. (2020). Does your child think you're happy? Exploring the associations between children's happiness and parenting styles. Children and Youth Services Review, 105074. https://doi.org/10.1016/j.childyouth.2020.105074.

Matias, M., Ferreira, T., Vieira, J., Cadima, J., Leal, T., \& Mena Matos, P. (2017a). Workplace family support, parental satisfaction, and workfamily conflict: Individual and crossover effects among dual-earner couples. Applied Psychology, 66, 628-652. https://doi.org/10.1111/ apps.12103.

Matias, M., Ferreira, T., Vieira, J., Cadima, J., Leal, T., \& Matos, P. (2017b). Work-family conflict, psychological availability, and child emotion regulation: Spillover and crossover in dual-earner families. Personal Relationships, 24(3), 623-639. https://doi.org/10.1111/ pere. 12198.

Mauno, S., Hirvonen, R., \& Kiuru, N. (2018). Children's life satisfaction: The roles of mothers' work engagement and recovery from work. Journal of Happiness Studies, 19(5), 1373-1393. https://oi.org/10. 1007/s10902-017-9878-6.

Meier, A., Musick, K., Fischer, J., \& Flood, S. (2018). Mothers' and Fathers' well-being in parenting across the arch of child development. Journal of Marriage and Family, 80(4), 992-1004. https:// doi.org/10.1111/jomf.12491.

Moreno, M., \& Londoño-Pérez, C. (2017). Family and personal predictors of eating disorders in young people. Anales de Psicología, 33(2), 235-242. https://doi.org/10.1037/t06040-000.

Muthén, B., \& Muthén, L. K. (2000). Integrating person-centered and variable-centered analyses: Growth mixture modeling with latent trajectory classes. Alcoholism: Clinical and Experimental Research, 24(6), 882-891. https://doi.org/10.1111/j.1530-0277. 2000.tb02070.x.

Nepper, M. J., \& Chai, W. (2016). Parents' barriers and strategies to promote healthy eating among school-age children. Appetite, 103, 157-164. https://doi.org/10.1016/j.appet.2016.04.012.

Olson, D. H. (2000). Circumplex model of marital and family systems. Journal of Family Therapy, 22(2), 144-167. https://doi.org/10. 1111/1467-6427.00144.

Olson, D. H., Waldvogel, L., \& Schlieff, M. (2019). Circumplex model of marital and family systems: An update. Journal of Family Theory \& Review, 11(2), 199-211. https://doi.org/10.1111/jftr.12331.

Pavot, W., \& Diener, E. (2008). The satisfaction with life scale and the emerging construct of life satisfaction. The Journal of Positive Psychology, 3(2), 137-152. https://doi.org/10.1080/ 17439760701756946.

Pérez-Fuentes, M., Jurado, M., Linares, J., Ruiz, N., Márquez, M., \& Saracostti, M. (2019). Parenting practices, life satisfaction, and the role of self-esteem in adolescents. International Journal of Environmental Research and Public Health, 16, 4045. https://doi. org/10.3390/ijerph16204045. 
Pollmann-Schult, M. (2014). Parenthood and life satisfaction: Why don't children make people happy? Journal of Marriage and Family, 76(2), 319-336. https://doi.org/10.1111/jomf.12095.

Rad, M. S., Martingano, A. J., \& Ginges, J. (2018). Toward a psychology of Homo sapiens: Making psychological science more representative of the human population. Proceedings of the National Academy of Sciences of the United States of America [PNAS], 115(45), 11401-11405. https://doi.org/10.1073/pnas.1721165115.

Rajani, N. B., Skianis, V., \& Filippidis, F. T. (2019). Association of environmental and sociodemographic factors with life satisfaction in 27 European countries. BMC Public Health, 19(1), 534. https:// doi.org/10.1186/s12889-019-6886-y.

Rasmussen, M., Pedersen, T. P., Johnsen, N. F., Krølner, R. F., \& Holstein, B. E. (2018). Persistent social inequality in low intake of vegetables among adolescents, 2002-2014. Public Health Nutrition, 21(9), 1649-1653. https://doi.org/10.1017/S136898001800040X.

Richter, N., Bondü, R., Spiess, C. K., Wagner, G. G., \& Trommsdorff, G. (2018). Relations among maternal life satisfaction, shared activities, and child well-being. Frontiers in Psychology, 9, 739. https://doi. org/10.3389/fpsyg.2018.00739.

Schnettler, B., Miranda, H., Sepúlveda, J., \& Denegri, M. (2011). Satisfacción con la alimentación y la vida, un estudio exploratorio en estudiantes de la Universidad de La Frontera, Temuco- Chile. Psicologia \& Sociedade, 23(2), 426-435. https://doi.org/10.1590/ S0102-71822011000200024.

Schnettler, B., Lobos, G., Miranda-Zapata, E., Denegri, M., Ares, G., \& Hueche, C. (2017a). Diet quality, satisfaction with life, family life and food-related life across families: A cross-sectional study with mother-father-adolescent triads. International Journal of Environmental Research and Public Health, 14(11), 1313. https:// doi.org/10.3390/ijerph14111313.

Schnettler, B., Miranda-Zapata, E., Grunert, K. G., Lobos, G., Denegri, M., Hueche, C., \& Poblete, H. (2017b). Life satisfaction of university students in relation to family and food in a developing country. Frontiers in Psychology, 8, 1522. https://doi.org/10.3389/fpsyg. 2017.01522.

Schnettler, B., Miranda-Zapata, E., Lobos, G., Saracostti, M., Denegri, M., Lapo, M., \& Hueche, C. (2018). The mediating role of family and food-related life satisfaction in the relationships between family support, parent work-life balance and adolescent life satisfaction in dual-earner families. International Journal of Environmental Research and Public Health, 15, 2549. https://doi.org/10.3390/ ijerph15112549.

Schnettler, B., Grunert, K. G., Lobos, G., Miranda-Zapata, E., Denegri, M., Ares, G., \& Hueche, C. (2018a). A latent class analysis of family eating habits in families with adolescents. Appetite, 129, 37-48. https://doi.org/10.1016/j.appet.2018.06.035.

Schnettler, B., Grunert, K, G., Lobos, G., Miranda-Zapata, E., Denegri, M., Hueche, C. (2018b). Exploring relationships between family food behaviour and well-being in single-headed and dual-headed households with adolescent children. Current Psychology. https:// doi.org/10.1007/s1214.

Schnettler, B., Rojas, J., Grunert, K. G., Lobos, G., Miranda-Zapata, E., Lapo, M., \& Hueche, C. (2019). Family and food variables that influence life satisfaction of mother-father-adolescent triads in a south American country. Current Psychology. https://doi.org/10. 1007/s12144-019-00328-4.

Schnettler, B., Miranda-Zapata, E., Grunert, K. G., Lobos, G., Lapo, M., \& Hueche, C. (2020). Testing the spillover-crossover model between work-life balance and satisfaction in different domains of life in dual-earner households. Applied Research in Quality of Life. https://doi.org/10.1007/s11482-020-09828-z.
Schnitzlein, D. D., \& Wunder, C. (2016). Are we architects of our own happiness? The importance of family background for well-being. The B.E. Journal of Economic Analysis \& Policy, De Gruyter, 16(1), 125-149. https://doi.org/10.1515/bejeap-2015-0037.

Sharif, M. Z., Alcalá, H. E., Albert, S. L., \& Fischer, H. (2017). Deconstructing family meals: Do family structure, gender and employment status influence the odds of having a family meal? Appetite, 114, 187-193. https://doi.org/10.1016/j.appet.2017.03. 032.

Smilkstein, G. (1978). The family APGAR: A proposal for a family function test and its use by physicians. The Journal of Family Practice, 6(6), 1231-1239.

Szcześniak, M., \& Tułecka, M. (2020). Family functioning and life satisfaction: The mediatory role of emotional intelligence. Psychology Research and Behavior Management, 13, 223. https://doi.org/10. 2147/PRBM.S240898.

Tammelin, M., Malinen, K., Rönkä, A., \& Verhoef, M. (2017). Work schedules and work-family conflict among dual earners in Finland, the Netherlands, and the United Kingdom. Journal of Family Issues, 38(1), 3-24. https://doi.org/10.1177/0192513X15585810.

Tein, J. Y., Coxe, S., \& Cham, H. (2013). Statistical power to detect the correct number of classes in latent profile analysis. Structural Equation Modeling: A Multidisciplinary Journal, 20(4), 640-657. https://doi.org/10.1080/10705511.2013.824781.

Telef, B. B., \& Furlong, M. J. (2017). Social and emotional psychological factors associated with subjective well-being: A comparison of Turkish and California adolescents. Cross-Cultural Research, 51(5), 491-520. https://doi.org/10.1177/1069397117694815.

Terrazas-Carrillo, E., McWhirter, P. T., \& Muetzelfeld, H. K. (2016). Happy parents in Latin America? Exploring the impact of gender, work-family satisfaction, and parenthood on general life happiness. International Journal of Happiness and Development, 3(2), 140 161. https://doi.org/10.1504/IJHD.2016.079596.

Thege, B. K., Littvay, L., Tarnoki, D. L., \& Tarnoki, A. D. (2017). Genetic and environmental effects on eudaimonic and hedonic well-being: Evidence from a post-communist culture. Current Psychology, 36(1), 84-89. https://doi.org/10.1007/s12144-0159387-x.

Thomas, P., Liu, H., \& Umberson, D. (2017). Family relationships and well-being. Innovation in Aging, 1(3), 1-11. https://doi.org/10.1093/ geroni/igx025.

Tisdale, S., \& Pitt-Catshupes, M. (2012). Linking social environments with the well-being of adolescents in dual-earner and single working parent families. Youth \& Society, 44, 118-140. https://doi.org/10. 1177/0044118X10396640.

Turkdogan, T., Duru, E., \& Balkis, M. (2019). Circumplex model of family functioning in Turkish culture: Western family systems model in a Eurasian country. Journal of Comparative Family Studies, 50(2), 183-199. https://doi.org/10.3138/jcfs.50.2.005.

Utter, J., Larson, N., Berge, J. M., Eisenberg, M. E., Fulkerson, J. A., \& Neumark-Sztainer, D. (2018). Family meals among parents: Associations with nutritional, social and emotional wellbeing. Preventive Medicine, 113, 7-12. https://doi.org/10.1016/j.ypmed. 2018.05.006.

Vaqué-Crusellas, C., González, M., \& Casas, F. (2015). Does satisfaction with food matter? Testing the personal well-being index-school children (PWI-SC) with an additional item on satisfaction with food on a sample of 10 to 12-year-olds. Child Indicators Research, 8(4), 961973. https://doi.org/10.1007/s12187-015-9301-y.

Vermunt, J. K., \& Magidson, J. (2002). Latent class cluster analysis. In J. A. Hagenaars (Ed.), Applied latent class analysis (pp. 89-106). 
United Kingdom, UK: Cambridge University Press. https://doi.org/ 10.1017/CBO9780511499531.004.

Vieira, J. M., Matias, M., Lopez, F. G., \& Matos, P. M. (2016). Relationships between work-family dynamics and parenting experiences: A dyadic analysis of dual-earner couples. Work \& Stress, 30(3), 243-261. https://doi.org/10.1080/02678373.2016.1211772.

Vieira, J. M., Matias, M., Lopez, F. G., \& Matos, P. M. (2018). Workfamily conflict and enrichment: An exploration of dyadic typologies of work-family balance. Journal of Vocational Behavior, 109, 152 165. https://doi.org/10.1016/j.jvb.2018.10.007.
Zabriskie, R., \& McCormick, B. (2003). Parent and child perspectives of family leisure involvement and satisfaction with family life. Journal of Leisure Research, 35, 163-189. https://doi.org/10.1080/ 01494929.2013.768321.

Publisher's Note Springer Nature remains neutral with regard to jurisdictional claims in published maps and institutional affiliations. 